Vietnam Academy of Science and Technology
Vietnam Journal of Earth Sciences
http://www.vjs.ac.vn/index.php/jse

\title{
Land cover mapping in Yok Don National Park, Central Highlands of Viet Nam using Landsat 8 OLI images
}

\author{
Nguyen Viet Luong ${ }^{1,2^{*}}$, Ryutaro Tateishi², Akihiko Kondoh², Ngo Duc Anh ${ }^{4}$, Nguyen Thanh \\ Hoan ${ }^{3}$, Luu The Anh ${ }^{3}$ \\ ${ }^{1}$ Remote Sensing Application Department, Space Technology Institute, Vietnam Academy of Science and \\ Technology, 18 Hoang Quoc Viet str., Cau Giay dist., Hanoi, Vietnam \\ ${ }^{2}$ Center for Environmental Remote Sensing, Chiba University, 1-33 Yayoi-cho, Inage-ku, Chiba 263- \\ 8522, Japan \\ ${ }^{3}$ Institute of Geography, Vietnam Academy of Science and Technology, 18 Hoang Quoc Viet str., \\ Cau Giay dist., Hanoi, Vietnam \\ ${ }^{4}$ Vietnam National Space Center, Vietnam Academy of Science and Technology, 18 Hoang Quoc Viet str., \\ Cau Giay dist., Hanoi, Vietnam
}

Received 27 September 2016. Accepted 29 September 2017

\begin{abstract}
Over the past four decades, remote sensing has more useful and effective contributions in the classification, mapping of land cover, forest cover map. Out of these achievements, there are still limitations in the application, especially in the tropical region, because of the diversity and abundance of land cover objects, of course including tropical forests, where are the vegetation status varies due to the seasons of the year. In this study, we selected Landsat 8 satellite imagery from both dry and rainy seasons for the purpose of building detailed land cover maps of Yok Don National Park, Central Highlands of Vietnam where has two major forest types (a) deciduous broadleaf forest and (b) evergreen broadleaf forest. The land cover mapping was based on supervised classification approach. The results of forest cover area showed that total Evergreen broad-leaved forests (rich, medium and poor) area are 25,578 ha (22.14\%) and total Dry open dipterocarps forests (rich, medium and poor) area are 88,435 ha (76.54\%), and another object is $1,531.86$ ha $(1.33 \%)$. The detailed land cover map with the $15 \mathrm{~m}$ resolution provided and is useful for forest management in the study area. The results of the assessment accuracy of the land cover mapping showed that $88.37 \%$ of overall accuracy, $89.35 \%$ of producer accuracy, and $90.60 \%$ of user's accuracy.
\end{abstract}

Keywords: Landsat 8 OLI; Land cover mapping; Central Highlands; Vietnam.

(C)2017 Vietnam Academy of Science and Technology

\section{Introduction}

Detailed and accurate information of forest cover is important and necessary for science, management, conservation, reporting, and helps the policy makers to understand the en-

"Corresponding author, Email: nvluong@sti.vast.vn vironmental change dynamics to ensure sustainable development of forest resources (Gómez et al., 2016). The discrimination and mapping of the forest cover have been advanced with remotely sensed satellite technology from local to the global level (Patenaude et al., 2005; Annunzio et al., 2010; Tateishi et 
al., 2014). Forest is a dynamic feature on the land surface. As true for other land cover, forests to change in time and space. The changes may be positive as regrowth i.e., medium forest to dense forest, poor forest to medium and dense forest etc. or negative as deforestation i.e., logging, shifting cultivation, forest fire, the construction of buildings, urban expansion etc. According to FAO report on global forest resource assessment (FAO, 2015), global forest area fell by $3 \%$ from $4128 \mathrm{M}$ ha (1990) to $3999 \mathrm{M}$ ha (2015). The rate of net forest loss between 2010 and 2015 was half that in the 1990s. Net forest loss was mainly in the tropics; temperate forest area has increased. Rates of forest loss are highest in low-income countries (Keenan et al., 2015), and deforestation is continuing everywhere (Busch and Engelmann, 2015; FAO, 2015).

Today, optical remote sensing has become no stranger to the managers, scientists in areas such as forests, ecology, natural resources and the environment. Since 1972, the Landsat mission was first launched. The Landsat mission measured the Earth reflectance. Satellite image classification was done using the reflectance statistics for individual pixels. So far, optical and satellite imagery has proved its effectiveness in the establishment of resource maps, land use maps, forest cover maps, from the local to the global level.

Forest management is always required to obtain a map showing the details, high accuracy, and update information about the forest cover. Further detailed information on the forest is also well served for in-depth studies on biodiversity, ecology, habitat (Turner et al., 2003, Pham Ngoc Thach et al., 2014; Li et al., 2014). However, at present, the detailed land cover map is lacking in many where, even high conservation value forests such as national parks, etc., have caused many difficulties in forest management (Giri et al., 2003; Ridder, 2007; Verburg et al., 2011; Luong et al., 2015). The main causes for such a situation are the lack of funds for implementation, the satellite imagery data and the lack of human resources with remote sensing knowledge working at forest management agencies (Luong et al., 2015).

Landsat 8 satellite sensor is part of the Landsat Data Continuity Mission was successfully launched on February 11, 2013, from Space Launch Complex-3, Vandenberg Air Force Base in California and will join Landsat 7 satellite in orbit. Landsat 8 satellite has two main sensors: the Operational Land Imager (OLI) and the Thermal Infrared Sensor (TIRS). OLI will collect images using nine spectral bands in different wavelengths of visible, near-infrared, and shortwave light to observe a 185 kilometer (115 miles) wide swath of the Earth in 15-30 meter resolution covering wide areas of the Earth's landscape while providing sufficient resolution to distinguish features like urban centers, farms, forests and other land uses (NASA, 2017). One thing is important that satellite imagery data from Landsat 8 is completely free for users on a worldwide. There have been several studies using Landsat 8 for land cover classification and monitoring land cover and showed has the good potential (Roy et al., 2014; Jia et al., 2014; Dinh, 2016; Firoozynejad et al., 2017).

Currently, there is three main methodologies and dissemination in the use of image classification in remote sensing technology to classify vegetation as (i) Unsupervised image classification; (ii) Supervised image classification and (iii) Object-based image analysis. In this study, we used the supervised image classification approach. The supervised classification usually gives the best results, and the steps including select training areas, generate the signature file and classify.

The objective of this research was to use image data from the Landsat 8 satellite for developing the more detailed land cover map in Yok Don National Park, Central Highlands in Vietnam, where there are two seasons the dry season and the rainy season, and has two major forest types (a) deciduous broadleaf forest and (b) evergreen broadleaf forest. 
Vietnam Journal of Earth Sciences, 39(4), 393-406

\section{Study area and data}

\subsection{Study area}

The Yok Don National Park in the Central Highlands region lies between $12^{\circ} 45^{\prime}$ $13^{\circ} 10^{\prime}$ north latitude and $107^{\circ} 29^{\prime}-107^{\circ} 48^{\prime}$ ' east longitude and it is the largest national park in Vietnam.

Thai Van Trung, 1998; Phung Ngoc Lan et al., 2006, Nguyen Nghia Thin et al., 2008 have classified the forest of Yok Don National Park into two major types of forest: (a) deciduous broadleaf forest, and the dominant tree species in the deciduous broadleaf forest are Dipterocarpus tuberculatus, Dipterocarpus obtusifolius, Terminalia tomentosa, and Shorea obtuse; (b) evergreen broadleaf forest, and the evergreen broadleaf forest mainly comprises of Michelia mediocris, Cinamomum iners, Syzygium zeylanicum,
Syzygium wightianum, Garruga pierrei, Gonocaryum lobbianum, Schima superba, Camellia assamica, and Lithocarpus fenestratus.

Soil type of the forest inside the park has diverse types of soils including brown, redyellow, and black soils (MARD, 2010). The topography of this park contains relatively plain topography and is located at an altitude of 200-300 m above sea level (Nguyen Xuan Canh et al., 2009).

The climate of this region is tropical monsoon type which has a well-defined dry season between October and April, and typical rainy season between May and November. The mean annual rainfall is $1540 \mathrm{~mm}$, and mean monthly temperature is around $25^{\circ} \mathrm{C}$ (Nguyen Xuan Canh et al., 2009).

The location map of the Yok Don National Park is shown in Figure 1.

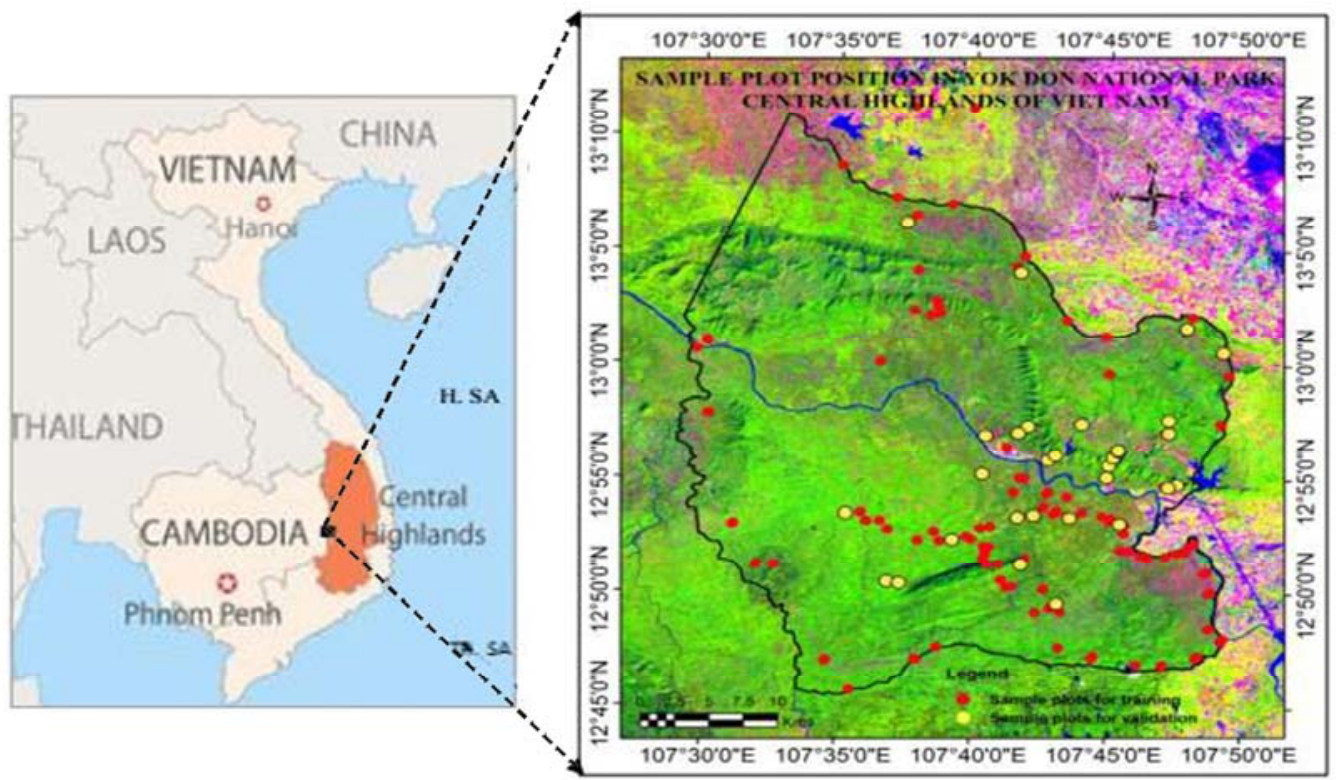

Figure 1. Location map and sample plot positions based on Landsat 8 composite imagery of the study area (red point are sample plots for training and yellow points are sample plots for validation).

The boundary of Yok Don National Park is shown in the black polygon in the right image

\subsection{Satellite data}

The study has used the satellite imagery of Landsat 8 Operational Land Imager (OLI) in
February 2014 (dry season) and October 2015 (rainy season). The resolution of band 4 (wavelength: 0.65-0.67) and band 5 (wav 
Nguyen Viet Luong, et al./Vietnam Journal of Earth Sciences 39 (2017)

length: $0.85-0.88)$ is 30 meters, band 8/Panchromatic (wavelength: $0.5-0.68$ ) is 15 meters. The reason for the choice of two time-scene image, that, due to the characteristics of the study area includes two types of forest are Evergreen broad-leaved forest and Dry open dipterocarps forest. Therefore, I chose two scenes images at two different times (dry season in 2014 and rainy season in 2015). The Landsat 8 in the dry season to distinguish between and evergreen forests of deciduous forest. Both of Landsat 8 images used in this study area is cloud free. The technical details of the satellite data used in the present study are shown in Table 1 and Figure 2.

Table 1. Landsat 8 OLI data used in this research

\begin{tabular}{|c|c|c|c|c|c|}
\hline No & ID & Observation date & Path/ Row & Band used & Season \\
\hline 1 & LC81240512015289LGN00 & 2015-10-16 & $124 / 051$ & B4, B5, B6, B8 & Rainy \\
\hline 2 & LC81240512014030LGN00 & 2014-01-30 & $124 / 051$ & $\mathrm{~B} 4, \mathrm{~B} 5, \mathrm{~B} 6, \mathrm{~B} 8$ & Dry \\
\hline
\end{tabular}

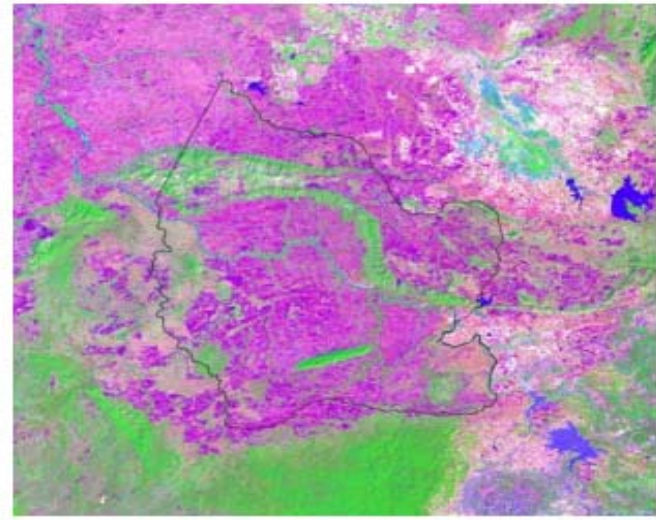

(a)

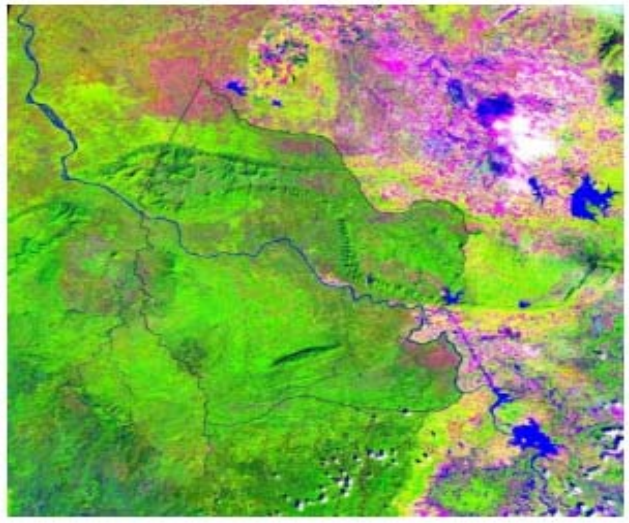

(b)

Figure 2. Landsat 8 OLI used in this study: (a) Dry season in 2014 (b) Rainy season in 2015

\section{Method for land cover mapping}

\subsection{Land cover classification system}

In this study we have applied to the land cover classification systems of the UNESCO (1973) and Thai Van Trung (1998) for the classification into 2 main classes of land cover and then used the Circular No.34/TT-BNN issued by Ministry of Agriculture and Rural Development (MARD) of Vietnamese government (2009) for the detailed classification into 6 classes of forest cover with the rich forest comprised a forest with a standing wood volume over $301 \mathrm{~m}^{3} \cdot \mathrm{ha}^{-1}$, the medium forest with 101-300 $\mathrm{m}^{3} \cdot \mathrm{ha}^{-1}$ and the poor forest included the forest with $0-100 \mathrm{~m}^{3} \cdot \mathrm{ha}^{-1}$. Although according to the Circular 34 , there is a very rich forest class with wood volume over $300 \mathrm{~m}^{3} \cdot \mathrm{ha}^{-1}$, we have not classified it. Because, this kind of class area is not much, and there is no appearance in Dipterocarps forest in this study area, therefore, we have included rich forest and very rich forest, and called them rich forest class. The forest in this ecosystem zone was classified into 6 classes such as (1) Evergreen broad-leaved rich forest (EB rich forest), (2) Evergreen broad-leaved medium forest (EB medium forest), (3) Evergreen broad-leaved poor forest (EB poor forest), (4) Dry open dipterocarps rich forest, (5) Dry open dipterocarps medium forest (DD medium forest) and (6) Dry open dipterocarps poor forest (DD poor forest) (Luong et al., 2015). According to UNESCO (1973), other land cover categories 
Vietnam Journal of Earth Sciences, 39(4), 393-406

may be identified as- (7) Other land cover (mainly composed of woody tree from 0.5 to $5 \mathrm{~m}$ tall); scrubland, (most of the individual shrubs not touching each other, often with a grass stratum); Thicket (individual shrubs interlocked and barren land) and (8) Waterbody. The detailed forest cover's classification is shown in Table 2 (Luong et al., 2015).

Table 2. Classification of forest cover for the study area (Luong et al., 2015)

\begin{tabular}{|c|c|}
\hline UNESCO (1973), Trung (1998) and Luong et al., (2015) & Circular No. 34/TT-BNN issued by MARD (2009) \\
\hline \multirow{3}{*}{ Evergreen broad-leaved forest (EB forest) } & 1. EB Rich forest \\
\hline & 2. EB Medium forest \\
\hline & 3. EB Poor forest \\
\hline \multirow{3}{*}{ Dry open dipterocarps forest (DD forest) } & 4. DD Rich forest \\
\hline & 5. DD Medium forest \\
\hline & 6. DD Poor forest \\
\hline Other land cover & 7. Other land cover \\
\hline Water body & 8. Water body \\
\hline
\end{tabular}

\subsection{Pre-processing satellite data}

The method of satellite images processing in this study includes: Geometric correction, Image to map rectification by terrain map sheet on scale 1:50,000, and image fusion, in there: panchromatic sharpening is an image

fusion method in which high-resolution panchromatic data is fusion with lower resolution multispectral data to create a colorized highresolution dataset (Laben et al., 2000). The result of before and after the panchromatic sharpening of Landsat 8 is shown in Figure 3 below:

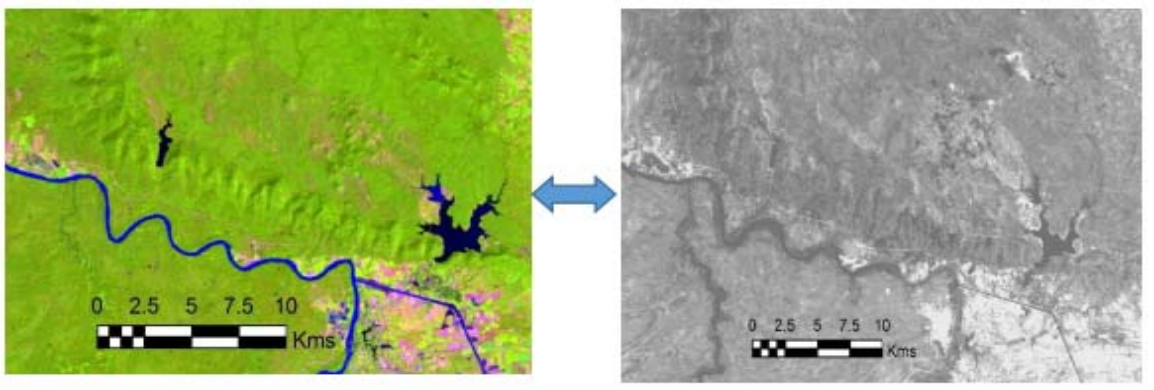

(a)

(b)

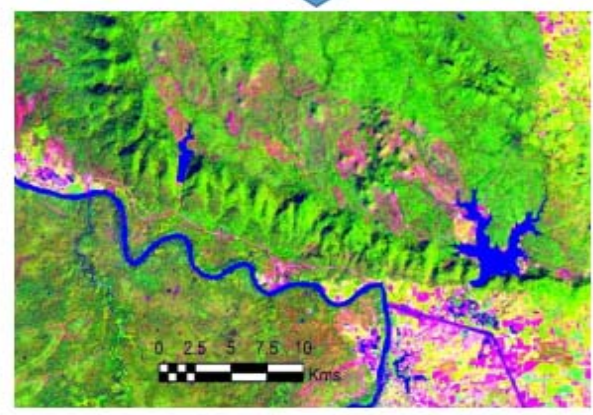

(c)

Figure 3. An example of panchromatic sharpening: (a) Original color image- $30 \mathrm{~m}$ resolution, (b) Panchromatic image-15 m resolution, (c) Pan-sharpened color image-15 m resolution 
Nguyen Viet Luong, et al./Vietnam Journal of Earth Sciences 39 (2017)

The NDVI image in dry season makes up from Red band (band 4) and Near Infrared band (band 5) from Landsat 8 OLI satellite. From Landsat 8 in dry season can be clearly distinguished between an evergreen forest of deciduous forest based on NDVI value, from the NDVI image (Figure 4), the green color is evergreen forest with the NDVI value from
0.0 to 1.0 , and yellow color is mainly deciduous forest with the NDVI value from -1.0 to 0 . The difference between the two major forest types within the study area (a) deciduous broadleaf forest and (b) evergreen broadleaf forest during the dry season. Photos were taken in the dry season (April 2015), Figure 5.

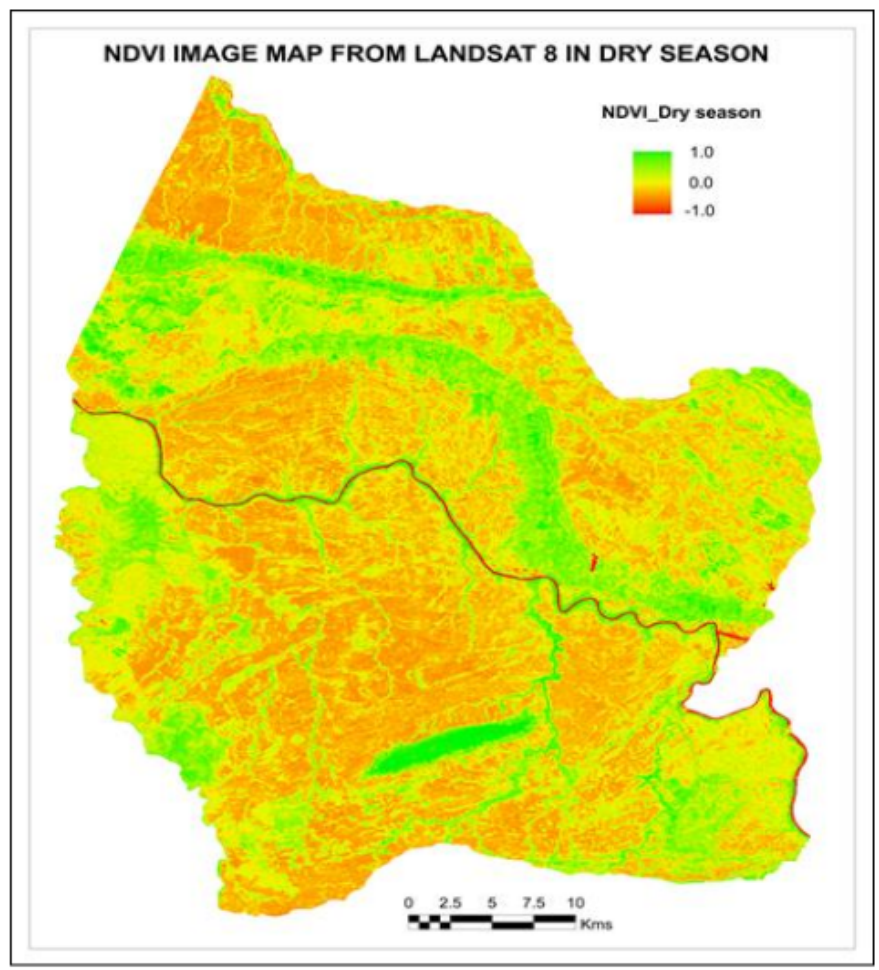

Figure 4. NDVI image of Yok Don National Park in dry season

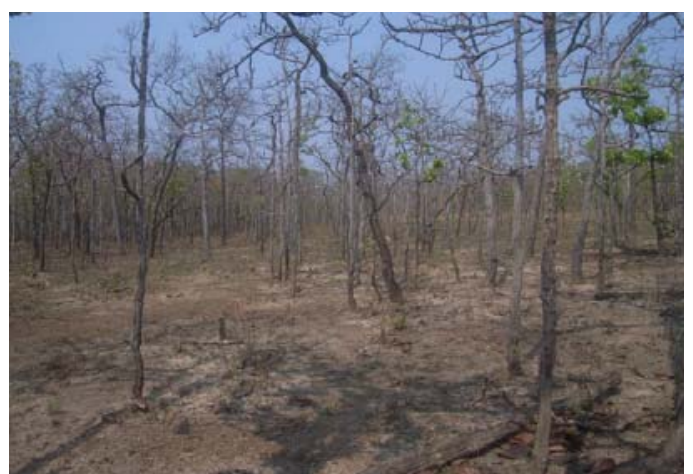

(a)

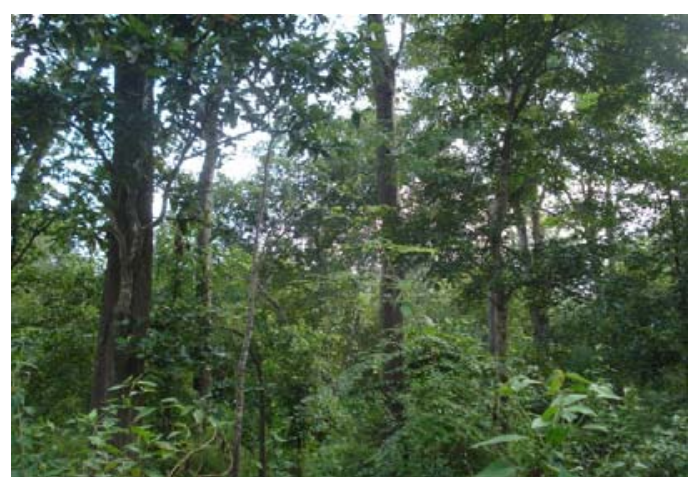

(b)

Figure 5. Photos of two major forest types (a) deciduous broadleaf forest and (b) evergreen broadleaf forest 
Vietnam Journal of Earth Sciences, 39(4), 393-406

\subsection{Reflection spectrum analysis}

Develop a reflectance spectral value graph to denote different forest objects (rich, medium and poor) in the set of surveyed samples. That is, at each of the sample plot sites, we have created a square sized according to the sample plot size. Sample plots were selected into 3 forest categories according to the field calculation: rich forest, medium forest, poor forest.

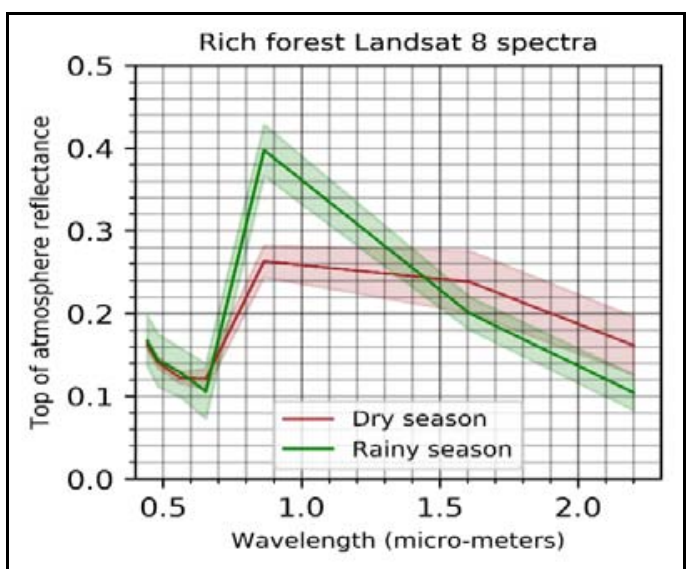

(a) Rich forest

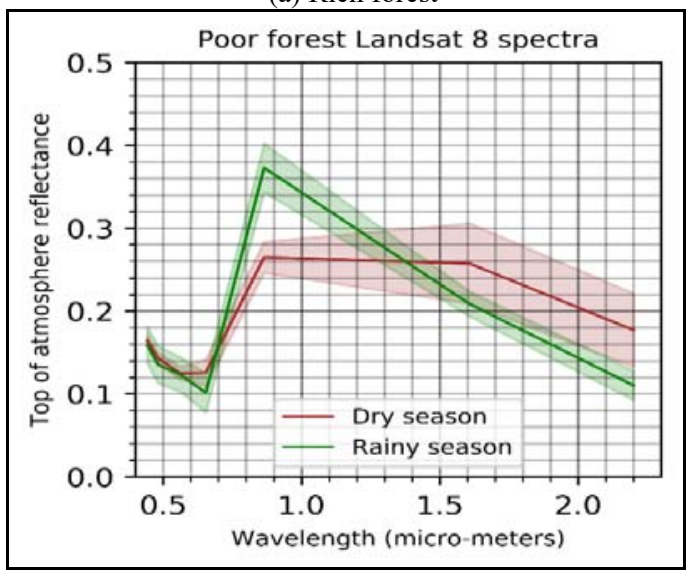

(c) Poor forest

A GPS Garmin-GPSMAP87S instrument was used to determine the center position of each sample plot. We carefully have chosen the sample plot position with a homogenous area of the forest cover and at least $100 \mathrm{~m}$ distant from other features such as trails, roads,
These squares will then be overlaid on the Landsat 8 satellite image to calculate the spectral value. For each set of sample plots (rich, medium, poor), we will create a "mask" class to calculate the spectral value using the "Compute statistics" tool on ENVI software. The spectral value on the histogram is calculated for all sample plot of the same forest type. See an example in Figure 6.

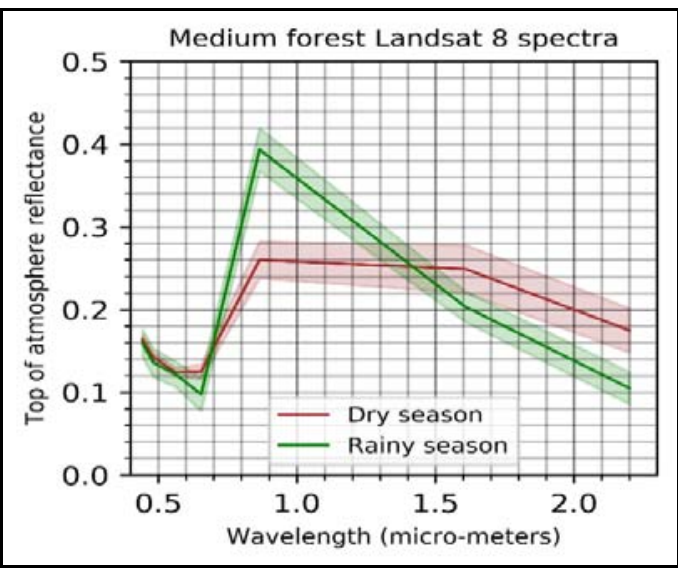

(b) Medium forest

Figure 6. Spectrum reflected from Landsat 8 satellite image: (a) Rich forest; (b) Medium forest and (c) Poor forest

\subsection{Field work}

Field survey is important for collecting in situ data required for accurate analysis of the satellite based estimates. We organized an intensive field campaign during April 2015 to collect the ground truth data. In total, there are 110 sample plots were established in the study area. The size of the sample plots is 1 ha $(100 \times$ $100 \mathrm{~m})$. We measured the diameter at breast height $1.3 \mathrm{~m}$ (D1.3) using Criterion RD 1000 laser instrument and height $(\mathrm{H})$ using Trupulse 360 Laser height instrument.

streams, rivers, water bodies, and other features. The authors also recorded the types of tree species during the field inventory following the Vietnam Flora book. All species were recorded and the taxonomy used was the Flora of Vietnam book (Hoang Pham, 1999-2000). 
The distribution of sample plot positions are shown in Figure 1, and the sample plot distribution at each class of forest was used in the classification as shown in Table 3.

Table 3. The sample plot distribution used in the classification (traing data)

\begin{tabular}{|c|c|c|}
\hline No. & Class & $\begin{array}{c}\text { Total sample } \\
\text { plots }\end{array}$ \\
\hline 1 & Rich forest $\left(>300 \mathrm{~m}^{3} \cdot \mathrm{ha}^{-1}\right)$ & 18 \\
\hline 2 & Medium forest $\left(101-200 \mathrm{~m}^{3} \cdot \mathrm{ha}^{-1}\right)$ & 71 \\
\hline 3 & Poor forest $\left(0-100 \mathrm{~m}^{3} \cdot \mathrm{ha}^{-1}\right)$ & 21 \\
\hline & Total & 110 \\
\hline
\end{tabular}

\subsection{Supervised classification (Maximum} likelihood)

Supervised classification can be defined normally as the process of the sample of known identity to classify pixels of unknown identity. Samples of known identity are those pixels located within training areas. Supervised classification procedures are the essential analytical tools used for the extraction of quantitative information from remotely sensed image data. The user closely controls the supervised classification method. An important assumption in supervised classification usually adopted in remote sensing is that each spectral class can be described by a probability distribution in multispectral space, it also is important to have a set of desired classes in mind, and then create the appropriate signatures from the data. You must also have some way of recognizing pixels that represent the classes that you want to extract.

Supervised classification is usually appropriate when we want to identify relatively few and detailed classes of object, when we have selected training sites that can be verified with ground truth data, or when we can identify distinct, homogeneous regions that represent each class. On the other hand, if we want the classes to be determined by spectral distinctions that are inherent in the data so that you can define the classes later, then the application is better suited to unsupervised training. Use unsupervised training to define many classes easily, and identify classes that are not in contiguous, easily recognized regions. The basic steps involved in typical supervised classification procedure as; (i) Define signatures, (ii) Evaluate signatures, and (iii) Process a supervised classification.

In this process, we select pixels that represent land cover features that we recognize, from ground truth data (sample plots system) in Yok Don National Park with the eight classes are (Luong et al., 2015);

Class1 - Evergreen broad-leaved rich forest (EB rich forest).

Class 2 - Evergreen broad-leaved medium forest (EB medium forest).

Class 3 - Evergreen broad-leaved poor forest (EB poor forest).

Class 4 - Dry open dipterocarps rich forest (DD rich forest).

Class 5 - Dry open dipterocarps medium forest (DD medium forest).

Class 6 - Dry open dipterocarps poor forest (DD poor forest), and

Class 7 - Other land cover and.

Class 8 - Waterbody.

The software used in this study for maximum likelihood is ERDAS image 2014 and for editor maps used ArcGIS 10.2 software.

\subsection{Accuracy assessment}

The accuracy refers to the success of estimating the true value of quality or parameter and can be obtained when all the units in the population are measured and when measurements are free of many sorts of biases. The best way to test the interpretation accuracy is to select a sample of points and check the classes as appearing on the map against the ground.

The independent validation sites as the second data set and will be used to assess the classification accuracy. The locations used for validation will not be the same as those used for classification training to avoid potential positive bias in the accuracy assessment. The 
Vietnam Journal of Earth Sciences, 39(4), 393-406

report will include an error matrix for all forest cover classes and other class. The error matrix will be used to derive the producer's and user's accuracy and the Kappa statistic for each class and overall accuracy. The accuracy report for the final classification is shown the Table 6 , section 4.2 of this paper.

\section{Results}

\subsection{The parameter of structure and biomass of forest}

The results from the sample plots were used to calculate the parameters of structure and woody volume of forest cover at Yok Don National Park for the current state of six forest cover types including (1) Evergreen broadleaved rich forest (EB rich forest); (2) Evergreen broad-leaved medium forest (EB medium forest); (3) Evergreen broad-leaved poor forest (EB poor forest); (4) Dry open dipterocarps rich forest (DD rich forest); (5) Dry open dipterocarps medium forest (DD medium forest) and (6) Dry open dipterocarps poor forest (DD poor forest). The parameters of the structure of forest cover including the diameter of breast height at $1.3 \mathrm{~m}$ position (D1.3>5 $\mathrm{cm}$ ), height at from bottom to top of the wood tree $(\mathrm{H})$, the density of wood tree/ha (N/ha).

The woody volume (V) of each tree was calculated by using the Equation (1) (FAOFRA, 2000; Vo Van Hong et al., 2006) which uses the basal area of a tree at breast height (G) in square meters (m2), total tree height (H) in meters $(\mathrm{m})$ and the conversion factor (F). It is worthful to mention that the wood volume (V) in Equation (1) (Vo Van Hong et al., 2006).

$$
\mathrm{V}=\mathrm{G} \times \mathrm{H} \times \mathrm{F}
$$

In Equations (1):

$\mathrm{V}$ is the woody volume $\left(\mathrm{m}^{3}\right)$

$\mathrm{G}$ is the basal area of tree at breast height $1.3 \mathrm{~m}$ in squared meters $\left(\mathrm{m}^{2}\right)$

$\mathrm{H}$ is the total tree height $(\mathrm{H})$ in meters $(\mathrm{m})$, and

$\mathrm{F}$ is the conversion factor $(\mathrm{F})$.

The results are shown in the Table 4.

Table 4. The parameters of the structure and woody volume of forest

\begin{tabular}{|c|c|c|c|c|c|}
\hline No. & Class & $\mathrm{D}_{1.3}(\mathrm{~cm})$ & $\mathrm{H}(\mathrm{m})$ & $\mathrm{N} / \mathrm{ha}\left(\right.$ tree $\mathrm{ha}^{-1}$ ) & $\mathrm{V}\left(\mathrm{m}^{3} \cdot \mathrm{ha}^{-1}\right)$ \\
\hline 1 & EB rich forest & 29.99 & 13.78 & 777.63 & 407.96 \\
\hline 2 & EB medium forest & 17.21 & 10.29 & 938.50 & 129.52 \\
\hline 3 & EB poor forest & 12.51 & 6.17 & 580.00 & 36.27 \\
\hline 4 & DD rich forest & 26.38 & 13.78 & 802.46 & 305.22 \\
\hline 5 & DD medium forest & 17.62 & 11.03 & 1048.61 & 151.65 \\
\hline 6 & DD poor forest & 13.18 & 7.79 & 1172.90 & 75.21 \\
\hline
\end{tabular}

\subsection{Land cover mapping}

The results of the land cover map based on supervised classification of Landsat 8 OLI, 2015 shown that the EB rich forest 7.79 thousand ha $(6.74 \%)$, EB medium forest area is 13.48 thousand ha (11.67\%), EB poor forest area is 3.72 thousand ha $(3.72 \%)$, DD rich forest area is 16.69 thousand ha (14.45\%) DD medium forest area is 50.09 thousand ha (46.05\%), DD poor forest area is 21.63 thousand ha $(18.73 \%)$, Other land cover area is $829.82 \mathrm{ha}(0.72 \%)$ and Water body area is 701 ha $(0.61 \%)$. The results of land cover mapping are shown in Table 5 and Figure 7.
The results from Table 5 and Histogram 1 are shown that total area of evergreen broadleaved forests is 25,578 ha $(22.14 \%)$ and the total area of dry open dipterocarps forests are 88,435 ha $(76.54 \%)$ and another object is $1,531.86$ ha $(1.33 \%)$. In there, medium forest (both EB and DD forest) occupies the largest area is $>55.03 \%$, and followed by the poor forest (both EB and DD forest) is $22.45 \%$ and the rich forest (both EB and DD forest) is $21.19 \%$. The final land cover map with the $15-\mathrm{m}$ resolution provided and is useful for forest management (Figure 7). 
We also used the 30 forest sample plots provided by the Forest Inventory and Planning Institute (FIPI, 2014) for estimating the accuracy of the classification method. The results of the assessment accuracy are shown in Table 6 below:

The results of the assessment accuracy of the land cover mapping in 2015 in Yok Don National Park are shown $88.37 \%$ as overall accuracy, $89.35 \%$ as producer accuracy and
$90.60 \%$ as user's accuracy. Although this research used satellite imagery from Landsat 8 OLI, however, the accuracy of the land cover map was not much different when compared to previous research also in this research area and used images 2004, 2010 from SPOT 5 satellite with $10 \mathrm{~m} \times 10$ resolution (Luong et al., 2015). Because, in this research, we used a quality sample plots and nearly double that in the previous research.

Table 5. Land cover area of Yok Don National Park in 2015

\begin{tabular}{cccc}
\hline No. & Class name & Area (ha) & Percent (\%) \\
\cline { 3 - 4 } \cline { 3 - 4 } 2 & EB rich forest & $7,790.38$ & 6.74 \\
3 & EB medium forest & $13,485.85$ & 11.67 \\
& EB poor forest & $4,301.92$ & 3.72 \\
4 & Sub-Total & $25,578.15$ & 22.14 \\
5 & DD rich forest & $16,699.52$ & 14.45 \\
6 & DD medium forest & $50,099.39$ & 43.36 \\
& DD poor forest & $21,636.60$ & 18.73 \\
7 & Sub-Total & $88,435.51$ & 76.54 \\
8 & Other land cover & 829.92 & 0.72 \\
& Water body & 701.94 & 0.61 \\
\hline
\end{tabular}

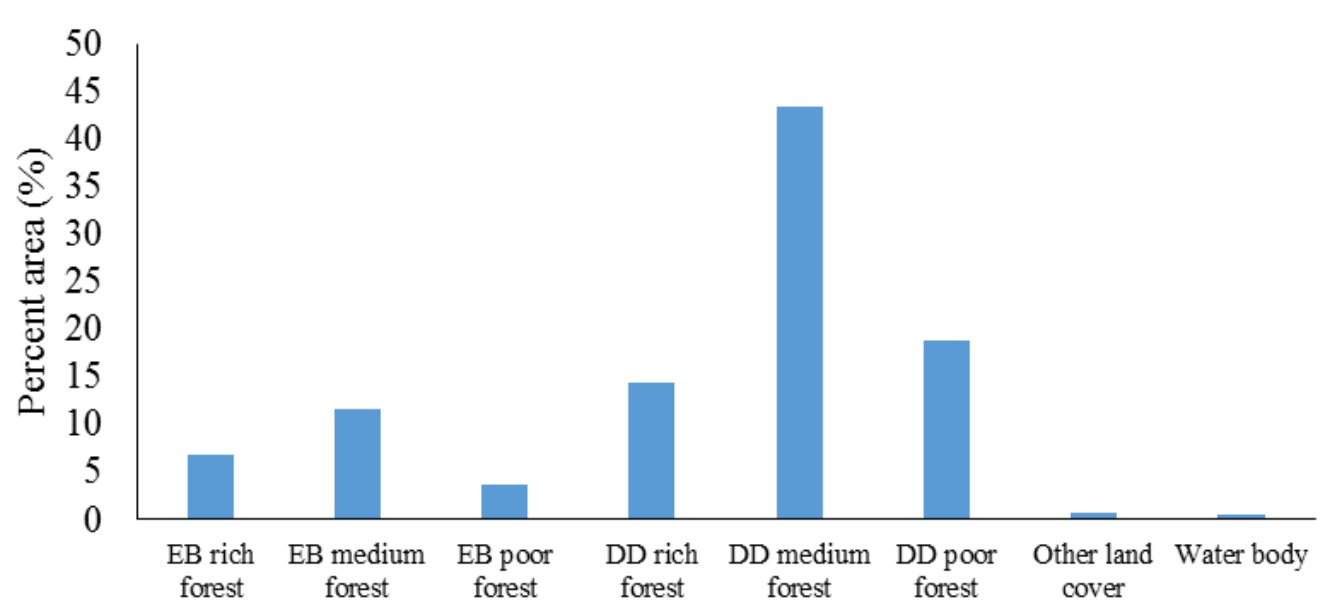

Histogram 1. Land cover area (\%) in Yok Don National Park in 2015

We also compared the classification results of this land cover map in this research with the results of the biomass map, which was done by the same author and the same study area (Luong and et al., 2016). If we put a regulation, biomass (Rich forest $>351 \mathrm{Mg}$. ha ${ }^{-1}$, Medium forest from $151-350 \mathrm{Mg}$. ha ${ }^{-1}$, Poor forest from $0-150 \mathrm{Mg} \cdot \mathrm{ha}^{-1}$ ) and woody volume (Rich forest $>301 \mathrm{~m}^{3} \cdot \mathrm{ha}^{-1}$, Medium forest from 101 $300 \mathrm{~m}^{3} \cdot \mathrm{ha}^{-1}$, Poor forest from $0-100 \mathrm{~m}^{3} \cdot \mathrm{ha}^{-1}$ ). The results of the comparison between two maps about forest cover area/biomass area have 
Vietnam Journal of Earth Sciences, 39(3), 393-406

shown that: Rich forest $(21.20 \% / 20.82 \%)$, Medium forest $(55.03 \% / 63.01 \%)$ and Poor forest $23.77 \% / 16.17 \%$ ). This comparison confirms that: There was not much difference about area from two maps and these results are reliable.

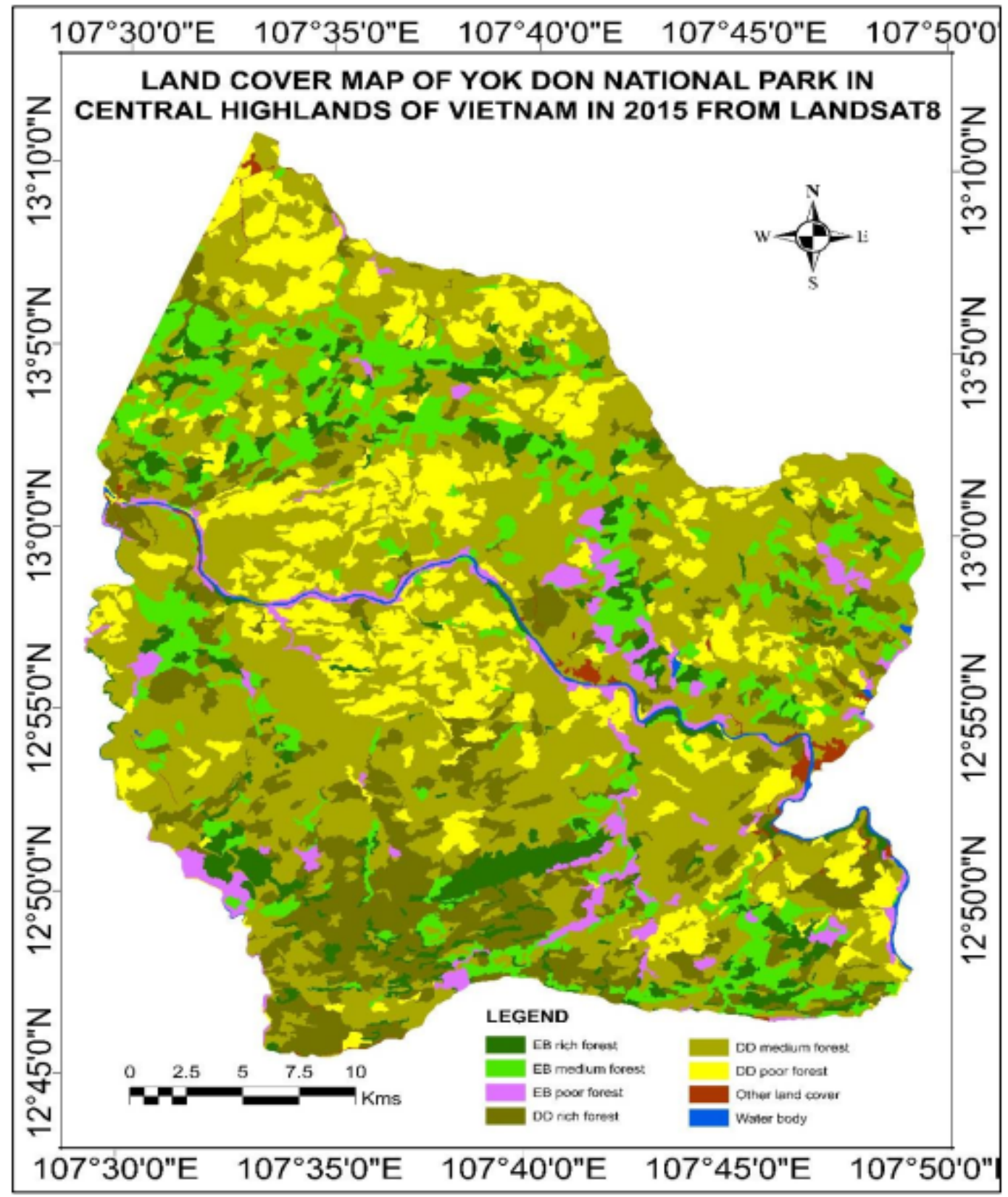

Figure 7. Land cover map of Yok Don National Park in Central Highlands of Vietnam 
Nguyen Viet Luong, et al./Vietnam Journal of Earth Sciences 39 (2017)

Table 6. Confusion matrixes for land cover classification of the Landsat 8 OLI data

\begin{tabular}{|c|c|c|c|c|c|c|c|c|c|c|}
\hline \multirow[b]{2}{*}{ Mapped class } & \multicolumn{9}{|c|}{ Ground truth } & \multirow[b]{2}{*}{ User accuracy } \\
\hline & $\begin{array}{c}\text { EB rich } \\
\text { forest }\end{array}$ & $\begin{array}{c}\text { EB medium } \\
\text { forest }\end{array}$ & $\begin{array}{c}\text { EB poor } \\
\text { forest }\end{array}$ & $\begin{array}{l}\text { DD rich } \\
\text { forest }\end{array}$ & $\begin{array}{l}\text { DD medium } \\
\text { forest }\end{array}$ & $\begin{array}{c}\text { DD poor } \\
\text { forest }\end{array}$ & $\begin{array}{c}\text { Other land } \\
\text { cover }\end{array}$ & $\begin{array}{l}\text { Water } \\
\text { body }\end{array}$ & Total & \\
\hline EB rich forest & 3 & & & & & & & & 3 & 100.00 \\
\hline EB medium forest & & 4 & & & & & & & 4 & 100.00 \\
\hline EB poor forest & & 1 & 4 & & & & & & 5 & 80.00 \\
\hline DD rich forest & & & & 4 & & & & & 4 & 100.00 \\
\hline DD medium forest & & & & & 9 & & & & 9 & 100.00 \\
\hline DD poor forest & & & & & 1 & 4 & & & 5 & 80.00 \\
\hline Other land cover & & & & & & & 5 & 1 & 6 & 83.33 \\
\hline Water body & & & & & & & 2 & 5 & 7 & 71.43 \\
\hline Total & 3 & 5 & 4 & 4 & 10 & 4 & 7 & 6 & 43 & \\
\hline & & & & & & & & & & $89.35^{-1}$ \\
\hline Producer' accuracy & 100.00 & 80.00 & 100.00 & 100.00 & 90.00 & 100.00 & 71.43 & 83.33 & & 90.60 \\
\hline Overall accuracy & 88.37 & & & & & & & & & \\
\hline
\end{tabular}

\section{Conclusions}

For developing a detailed forest cover map, where the region is the tropical monsoon, along of the rainy season and the dry season is distinctive, with evergreen and deciduous forests. The first: optical satellite data from the dry season to help us accurately distinguish of evergreen forests and deciduous forests. The results indicated that total Evergreen broad-leaved forests area are 25,578 ha (22.14\%) and total Dry open dipterocarps forests area are 88,435 ha $(76.54 \%)$ and another object is $1,531.86$ ha $(1.33 \%)$. The second: the combined with optical satellite data from the rainy season helps a detailed classification of classes from the evergreen forest and the deciduous forests. The detailed results indicated that Evergreen broad-leaved rich forest is 7.79 thousand ha (6.74\%), Evergreen broad-leaved medium forest area is 13.48 thousand ha $(11.67 \%)$, Evergreen broad-leaved poor forest area is 3.72 thousand ha $(3.72 \%)$, Dry open dipterocarps rich forest area is 16.69 thousand ha (14.45\%), Dry open dipterocarps medium forest area is 50.09 thousand ha (46.05\%), Dry open dipterocarps poor forest area is 21.63 thousand ha $(18.73 \%)$, another land cover area is 829.82 ha $(0.72 \%)$ and Waterbody area is 701 ha $(0.61 \%)$. The results of the assessment accuracy of the land cover mapping showed that $88.37 \%$ of overall accu- racy, $89.35 \%$ as producer accuracy, and $90.60 \%$ as user's accuracy. The detailed land cover map with the $15-\mathrm{m}$ resolution provided and is useful for forest management for the study area. This research concluded that: for the detailed classification of forest cover, where there are the rainy season and the dry season, and forest cover area has included both evergreen forest and deciduous forest, the choice of optical satellite data from both seasons is important and necessary.

\section{Acknowledgements}

The authors are grateful to the project No. VAST 01.03 15/16 from Vietnam Academy of Science and Technology (VAST) and Japan Society for the Promotion of Science (JSPS) for financial support to this research. We would like to thank USGS for providing Landsat 8 OLI data for this study.

\section{References}

Busch J. and Engelmann J., 2015. The Future of Forests: Emissions from Tropical Deforestation with and without a Carbon Price, 2016-2050. CGD Working p411. Washington, DC: Center for Global Development, 42p.

http://www.cgdev.org/publication/future-forests.

Circular 34/TT-BNN issued by Ministry of Agriculture and Rural Development of Vietnam (MARD) in 2009. Quy định tiêu chí xác định và phân loại rừng (in Vietnamese). Regulation on criteria for identify- 
Vietnam Journal of Earth Sciences, 39(3), 393-406

ing and classifying forest (in English) - Translated by Nguyen Viet Luong.

D’Annunzio R., Lindquist E., MacDicken K.G., 2014. Global forest land-use change from 1990 to 2010: an update to a global remote sensing survey of forests. Food and Agriculture Organization of the United Nations. Report from FAO and European Commission Joint Research Centre, 6p.

Nguyen Dinh Duong, 2016. Automated Classification of Land Cover Using Landsat 8 Oli Surface Reflectance Product and Spectral Pattern Analysis Concept-Case Study in Hanoi, Vietnam. International Archives of the Photogrammetry, Remote Sensing \& Spatial Information Sciences, 41.

FAO, 2015. Global Forest resources assessment 2015. How are the world's forests changing? FAO, Rome, 56p.

Firoozynejad M., Torahi A.A., 2017. Evaluation of IRS1D-LISS-III and Landsat 8-OLI Images for Mapping in Maroon Riparian Forest. Iran. J Geogr Nat Disast, 7(198), 2167-0587.

Giri C., Defourny P., Shrestha S., 2003. Land cover characterization and mapping of continental Southeast Asia using multi-resolution satellite sensor data. International Journal of Remote Sensing, 24(21), 4181-4196.

Gómez C., White J.C., Wulder M.A., 2016. Optical remotely sensed time series data for land cover classification: A review. ISPRS Journal of Photogrammetry and Remote Sensing, 116, 55-72.

Jia K., Wei X., Gu X., Yao Y., Xie X., Li B., 2014. Land cover classification using Landsat 8 operational land imager data in Beijing, China. Geocarto International., 29(8), 941-951.

Keenan R.J., Reams G.A., Achard F., De Freitas J.V., Grainger A., Lindquist E., 2015. Dynamics of global forest area: results from the FAO global forest resources assessment 2015. Forest Ecology and Management, 352, 9-20.

Laben C.A., Brower B.V., 2000. U.S. Patent No.6, 011, 875. Washington, DC: U.S. Patent and Trademark Office.

Li C., Wang J., Wang L., Hu L., Gong P., 2014. Comparison of classification algorithms and training sample sizes in urban land classification with
Landsat thematic mapper imagery. Remote Sensing, 6(2), 964-983.

Nguyen Viet Luong, Tateishi R., Nguyen Thanh Hoan, To Trong Tu, 2015. Forest Change and Its Effect on Biomass in Yok Don National Park in Central Highlands of Vietnam Using Ground Data and Geospatial Techniques. Advances in Remote Sensing, 4(2), 108-118.

Nguyen Viet Luong, Ryutaro Tateishi, Akihiko Kondoh, Ram C. Sharma, Nguyen Thanh Hoan, To Trong Tu, and Ho Tong Minh Dinh, 2016. Mapping tropical forest biomass by combining ALOS-2, Landsat 8, and field plots data. Land 31, 5(4). Doi:10.3390/land5040031.

NASA, 2017. https://landsat.gsfc.nasa.gov/operationalland-imager-oli/.

Nguyen Ngoc Thach, et al., 2014. Using NDVI differencing for mapping of depterocarp forest in Savanket province, Lao PDR. ACRS 20-08-2014.

Nguyen Nghia Thin, et al., 2008. Update Information of Flora and Plant's Resources of Yok Don National Park, DakLak Province in 2008. Report.

Nguyen Xuan Canh, et al., 2009. Report on Conservation Planning and Sustainable Development of Yok Don National Park in 2010-2020. Ministry of Agriculture and Rural Development of Vietnam: Hanoi, Vietnam.

Patenaude G., Milne R., Dawson T.P., 2005. Synthesis of remote sensing approaches for forest carbon estimation: reporting to the Kyoto Protocol. Environmental Science \& Policy, 8(2), 161-178.

Phung Ngoc Lan, et al., 2006. Natural forest ecosystems Viet Nam. Ministry of Agriculture and Rural Development of Vietnam (MARD). Technical report, 95p.

Ridder R.M., 2007. Global forest resources assessment 2010. Options and recommendations for a global remote sensing survey of forests. FAO For. Resour. Assess. Programme Work. Pap, 141.

Roy D.P., et al., 2014. Landsat-8: Science and product vision for terrestrial global change research. Remote sensing of Environment, 145, 154-172.

Tateishi R., Nguyen Thanh Hoan, Kobayashi T., Alsaaideh B., Tana G., D. Xuan Phong, 2014. Production of Global Land Cover Data-GLCNMO2008. Journal of Geography and Geology, 6(3), 99. Doi:10.5539/jgg.v6n3p99. 
Nguyen Viet Luong, et al./Vietnam Journal of Earth Sciences 39 (2017)

Thai Van Trung, 1998. Chapter IV. In The Tropical Forest Ecosystem in Vietnam, Science and Technics Publishing House, Hanoi, 291p.

Turner W., Spector S., Gardiner N., Fladeland M., Sterling E., Steininger M., 2003. Remote sensing for biodiversity science and conservation. Trends in ecology \& evolution, 18(6), 306-314.

UNESCO Paris, 1973. International classification and mapping of vegetation. Published by the United
Nations Educational, Scientific and Cultural Organization. ISBN 92-3-001046-4 LC No. 72-96442, 102, 13-37.

Verburg P.H., Neumann K., Nol L., 2011. Challenges in using land use and land cover data for global change studies. Global Change Biology, 17(2), 974-989.

Vo Van Hong, et al., 2006. Handbook for Vietnam forest inventory. Ministry of Agriculture and Rural Development of Vietnam (MARD), 95p. 